\title{
The Changing Face of a School Library with the Advent of E- Content
}

\author{
Naaz Kirmani \\ Head of Library Resource Center \\ Choithram International School, Indore \\ India
}

\begin{abstract}
The increased digitization has led to plethora of invaluable E-content, which lends itself for easy access and reference, economy of time, space \& efforts. With the realization of E-learning at higher education levels, the real challenge lies in designing an educational system with the flavor of E-learning at the primary level. This requires accurate assessment of educational needs, understanding of global benchmarks and the applicability of new technology to the E-learning. An assessment of E-learning and its applicability at primary education is provided. The role of the library and steps for its metamorphosis to the digital world is presented.
\end{abstract}

\section{Introduction}

The library resource center forms a focal point of learning in any educational organization. A well equipped and well managed library is the foundation of a modern educational system. Libraries in school, college, university or state level have served as the knowledge banks or repositories of information. The libraries of the past occupied large space with finite resources, but in the current era of networking, information sharing and digitization, libraries are shrinking in space but are growing infinitely in terms of handling resources. With the advent of computer networks and automation in the libraries since 1990s, the whole scenario has changed.

The structural and functional changes in the library have witnessed a shift in the role of librarian, from merely being a custodian of books to media specialists or information officers.

Further, with the development in Information Communication Technology (ICT), libraries world over need to be redefined and restructured to match the modern educational needs. Libraries are no longer looked as stand alone entities, which were once patronized by a handful of their ardent lovers. A library of the modern world can potentially be shrunk in size, exponentially scaled up in content and yet be made available to unlimited users at the click of a mouse 24 hours a day, 7 days a week, round the year. On one hand, the information proliferation or knowledge explosion has caused enormous growth in the volume of printed information, while on the other the advent of E-learning has led to an extensive adoption of computers in library management. In addition, the enhancement of information sharing networks has accelerated the transition of manual libraries to computer based units, due to which libraries are increasingly becoming part of larger library networks for enhancing their information services. 
Internet, E-learning, World Wide Web and other search engines have further opened the doors to a flood of information.

E-learning has emerged as a successful tool in modern educational system. The Eeducation concept has set new benchmarks in the higher education, mainly at college and university levels, where it has been embraced almost universally. However, the concept requires customization and a stepwise approach in order to cope with the needs and intellect of the children at the primary school level (age 3 11 years). The role of library becomes more important to provide this transition from a conventional classroom based learning system to the E-learning system. The following work presents an assessment of E-learning and its applicability to the primary level school education in India. The role of library and its utilization is discussed using the customized solutions for E-curriculum. A concept teaching model for Primary Years Programme (PYP) is presented.

\section{E-Learning}

E-learning or electronic learning is a term used to describe computer based or computer enhanced learning. E-learning encompasses use of a wide range of technological resources, which include videotape, internet, television, computer based training and variety of other audio and video based resources. The essence of the E-learning lies in its flexibility which makes it equally attractive and adaptable for distance and face to face learning. E-learning can take place either in synchronous or asynchronous form. The synchronous E-learning generally takes place in a classroom set up where a lecture is delivered by a teacher (or a trainer) and is broadcasted to all the students in different locations. .It overcomes the lack of interpersonal touch between the teacher \& pupils. The asynchronous learning is the most widely used form of E- learning where a student has access to the server based teaching modules at his/ her own convenience.

\section{Components of E-learning}

The primary components of the E-learning include an information source, information sink and a media to transmit the information from the source to the sink. The information source can be interactive (live classroom type) or non interactive (informational based). The interactive type sources provide ample opportunities for mutual interaction between the source and the sink, and hence these sources are sometimes more advantageous. However, non-interactive based sources are usually server based informational networks which can be used effectively in training, information sharing and other purposes where the mutual interaction is not of utmost important. The media requirements vary depending upon the use and purpose of the E-learning, but in general the requirements are audio visual and require network connectivity. The basic schematic representation of the E-learning is shown in Figure 1. 


\section{Pros and Cons of E-learning}

The major advantages of the E-learning include its strength to impart education without any geographical restriction, its unrestricted ability to neutralize the bottle necks arising due to the lack of qualified teaching staff, its immense strength in sharing the global resources from a single location, flexibility for the learner to choose the time, venue and source of information, courses etc, adaptability to suit the learner needs, diversity of informational sources and customized pace of learning as per the learner's needs and requirements.

Although, E-learning brings in immense advantages for modern education system but it has certain disadvantages as well. The major disadvantages include lack of interpersonal touch, high design times for learning modules, and high setup and operating costs. A summary of the advantages and disadvantages is presented in Table 1.

Insert Table 1 here

\section{E-learning for Primary School Level}

\section{Need for Customization}

The major challenge of E-learning setup lies in getting the user adaptable and comfortable with the process. Due to its limitation in mutual interaction, ironically E-learning creates a virtual barrier between the learner and the teacher. At primary school level, the student is in a developing state and is in the process of building acquaintance with different educational aspects hence the student requires physical presence of a teacher and interpersonal relationship at that impressionable age. Therefore, E- Learning as such may not be very effective means of imparting education at the primary level.

However, it is equally important to recognize that the student will potentially come across the E-learning system in near future. Hence it is important to design a system that can provide a smooth transition to the student from the conventional class room based learning to the Elearning stage. The required system should have the basic flavor of the E-learning and should provide a step wise transition to the student learning curve. This requires customization of the Elearning process by utilizing its constituents to mould the present educational system. For instance, the new system should bring the students closer to computer based learning environment, using a structured learning approach. It will help in developing the student's adaptability to the media based learning. Eventually, the new system should gradually step up the interaction level to provide a smooth transition to the students developing brain. This inculcates the necessity of E-curriculum in primary school education. Following elements are identified for effective implementation of E-curriculum.

- Digital Class room Modules

- School Library

- Concept Teaching Model for Primary Years Programme (PYP) 
These elements are identified based on the author's experiences in Indian primary schools. The digital class room modules and the school library form the core of the E-curriculum, while the PYP is identified as an element that can be used as an effective tool to promote E-curriculum. The constituents of the digital classroom modules (see later section), are considered as the harbinger of E-curriculum, due to which the digital class room module precedes the school library elements in terms of scheduling. The progression of E-curriculum and its elements are shown in Figure 2. These elements of the E-curriculum are discussed in detail in the following sections. It is recognized that due to variability in socio-economic structure in societies the rankings and the constituents of E-curriculum may change in other countries, thereby underlining the need of customization.

Insert Figure 2 here

\section{Digital Class Room Modules in E-curriculum}

The digital class room modules encompass a wide spectrum of technical resources, which include audio-visual aids, educational soft wares, Interactive media devices and laptops. Importantly these constituents require introduction at various stages of implementation, hence highlighting the need of prioritization. The prioritization will depend on several factors, including the existing infrastructure in the school, the experience and quality of the teaching staff, social background of students and other limitations such as financial bottlenecks. The generic prioritization for primary schools in India is presented in Figure 3.

\section{Insert Figure 3 here}

Figure 3 identifies and ranks six key constituents in order of the priority of implementation. A brief description of these constituents is presented.

Multi media Technology. This is recognized as a true harbinger of E-curriculum in primary education. It includes the use of audio visual aids like CDs, VCDs, DVDs, animated graphics technology to make the learning activities more interesting and meaningful for the students. Example- teaching a story in animated graphics with audio.

Hands on Computer lab. The students should be given access to the computers in labs where each student should have sufficient opportunity to learn and practice the computer skills. Example- play and practice type games to promote child's interest in computers.

Interactive White Board Technology. This is one of the most innovative methods of implementing E-curriculum at the school. It promotes students participation thereby making the classroom teaching more interactive. It can be used to screen a video/ graphical text from the internet/ intranet. Example- the student is asked to use a computer and access a story, which is already scanned and stored on the school server. 
Educational Soft wares. This is another method of creating media awareness and imparting teaching lessons to the students. Various educational soft wares are developed by different companies and are readily available in the market. The software uses "Fun n Learn" method thereby making the lessons more interesting for the students. Example- the student is asked to use a computer and answer a quiz.

Computer aided education in the classrooms. Different lessons can be planned and provided on intranet/ computers. After the delivery of lessons, the students can answer questions thereby providing a spot assessment of the learning. This helps the teacher in judging the comprehension skills and retention of the student immediately.

Laptop Culture. Another important way of promoting E-earning is to introduce laptops to the students in the schools. Each student should have a personal laptop to carry, which can be used for daily class room interactive modules.

\section{School Library}

As stated earlier, the school library forms the second most important element in implementation of E-curriculum. It not only provides plethora of resources to the students but it also provides a wealth of information to the staff members. The library can contribute in implementation of the E-curriculum in two key ways, namely by delivering information for effective design of digital class room modules and by providing an extensive network based information source to the students and the teachers. These two parameters necessarily raise the need of structural and functional changes in the conventional libraries. These changes are expected to be progressive in nature and should be implemented with the development of Ecurriculum. The author identifies the following constituents to bring about the desired changes in the library (listed in sequence of implementation).

- Library Automation

- Digital Library

- Digital Network Based Library

Library Automation. Advances in information processing \& retrieval system are keenly felt in the school libraries. The school libraries and school librarians both are faced with the challenging tasks of information management. The application of information technology based system for the management of the library systems and housekeeping operations (acquisition, cataloguing, serial control, circulation, stock checking) is known as library automation. The advantages of the automation includes efficient management of library inventory, ease in tracking of library resources, ease in access and referencing, centralized record keeping, speedy transaction and compatibility with e-resources. The schematic representation of an automated school library is presented in Figure 4. 
The automation in library can contribute immensely in the student's development and understanding of intranet based resources. It provides a simple and easy platform for the students to understand, grasp and get accustomed to the use of web based information. Together with digital class room modules it provides a two pronged approach to increase the adaptability in using E-resources. It also helps in boosting student's confidence and comfort in using other computer based learning modules in the curriculum. Altogether, the automation serves as important milestone before venturing into digitization of library.

Digital Library. The library automation provides an entry into a new learning atmosphere to the students but it is severely restricted by the limited availability of E-resources within the school setup. Also, the library automation does not provide all the printed media (books, magazines etc) in electronic form. Due to these reasons, digitization is often considered as a viable solution, especially in a small scale setup. The digitization of the library supplements the needs of E-curriculum in an efficient manner. The digitization involves conversion of printed resources to digital format, creation of meta-data, storage of appropriate repository and patron access or user interface. The digitization process is shown in Figure 5.

\section{Insert Figure 5 here}

The digitization can enhance the effectiveness and quality of digital classroom modules to a great extent. It provides the students an initial exposure of the E-resources based informational content. Since, the information is digitally available, the students have the option to access it remotely from anywhere within the school. This helps in developing the understanding of technological based resources among the students. It is therefore considered as an intermediate step between the automation and digital network based library.

Digital Network Based Library. The concept of the digital network based library is based on resource sharing. The information is essentially in electronic form, which is stored usually in one or more information centers. These information centers are connected with network and provide individual remote access to a member group of libraries. These user libraries should necessarily have local area network (LAN) based workstations to serve as conduits to the users. The major advantages of the digital network based library include access to vast holdings all over the world, availability of latest resources, availability of rare artifacts, no digitization of printed media required at school level, centralized quality control and economy of time, space and efforts at the school level. The schematic representation of a digital network based library is presented in Figure 6.

\section{Insert Figure 6 here}

Exposure to digital network based library is a defining milestone in implementing Ecurriculum. Since the network accessibility is limited to the relevant informational sources, it minimizes the risks of accidental access to undesirable information. Despite of the restricted access the student can get hands on experience in accessing remotely located informational sources by using computer based networks. However, in many places the limited availability of 
such networks may constraint its implementation. Fortunately, in India there are a number of available networks, these include British council library (BCL), Delnet, Nissat, Inflibnet (Information and Library Network), Calibnet (Calcutta Library Networks). These networks have been instrumental in lending their services to the smaller libraries within their region.

\section{Concept Teaching Model for Primary Years Programme (PYP)}

As discussed previously, the concept teaching model for PYP is the third important element that can be effectively used to implement E-curriculum at primary level. The PYP itself is a multi-facet program that lays emphasis on five elements namely, knowledge, concepts, skills, attitude and action. Due to its diverse contents, it can potentially provide variety in the digital class room modules and digital school library. A concept teaching model for PYP is presented.

\section{Insert Figure 7 here}

Figure 7 presents the schematic view of the concept teaching model for PYP. This model describes the curriculum delivery with E-content in a PYP classroom set up. Every classroom is equipped with computer based network that connects to a centralized information source (school server). The teacher can browse the subjects on the plasma screen after entering a particular class set up. Subcategories for each subject are also available. An enquiry based search engine is envisaged, the engine will filter the information by using the search string within a particular class curriculum. For instance, class 1 is doing an enquiry on animal homes then the model will extract, and display on plasma, the information on animal homes along with the picture of animals from the curriculum of class 1 . The same enquiry for a different class will show different search results.

Different graphical interfaces can be designed to suit the audience (depending on age). The model provides lessons on all the other subjects like Mathematics, General Knowledge, and Science and Foreign languages. The model is conceptual, and hence requires more research before implementation.

\section{Conclusions}

The success of E-learning at higher education level has created the need to implement a synchronous system at primary school level. The concepts of E-learning need customization to provide ample transition to the primary educational system. The customization needs are equally identifiable from children's perspective, who should be groomed in a step wise structured approach using E-curriculum. The three components of E-curriculum that can accomplish the desired goals are digital classroom modules, school library and a concept teaching model for primary years programme (PYP). The paper presents the key constituents of these elements in sequence of implementation. The author has put forth the measures that a school library may adopt to incorporate the latest trends in information technology in the modern system of education. The approach suggested in this paper can be used effectively for implementation of E- 
curriculum in primary schools in India. For other countries, the need of customization is highlighted.

\section{References}

Abraham, J. (1996). Computers in modernizing Library Information system and Services: Perspectives of Library Automation. International Library Movement.

Carliner, S. (2002). Designing E learning. ASTD Pub Dept.

Dania, M., B. (1997). Automating Media Centers and Small Libraries: A Microcomputer-based Approach. Libraries Unlimited.

Head, J.W., \& McCabe, G.B. (1996).Introducing and Managing Academic Library Automation Projects. Greenwood Pub, 1996. 
Table 1,

Summary of Advantages and Disadvantages of E-Learning

\begin{tabular}{|c|c|}
\hline \multicolumn{2}{|c|}{ Advantages of E-learning } \\
\hline $\begin{array}{l}\text { Geographically } \\
\text { dispersed pupils }\end{array}$ & $\begin{array}{l}\text { The developments in information technology enable the learners } \\
\text { who are residing in remote areas to avail the benefits of a formal } \\
\text { education just at a click of the mouse. }\end{array}$ \\
\hline $\begin{array}{l}\text { Deals with the } \\
\text { lack of qualified } \\
\text { teaching staff }\end{array}$ & $\begin{array}{l}\text { With E-learning technology stepping in, the unavailability of } \\
\text { qualified staff is no longer a bottle neck for the learning process. A } \\
\text { teacher can deliver lecture which get transmitted or broadcasted to } \\
\text { a large number of student body on a worldwide basis. }\end{array}$ \\
\hline - Resource sharing & $\begin{array}{l}\text { It encourages resource sharing by providing access to the large } \\
\text { reservoir of information (e.g. journals, articles, e-books etc) }\end{array}$ \\
\hline - Flexibility & $\begin{array}{l}\text { The learner can choose courses, modules etc according to his/ her } \\
\text { convenience at anytime of year or at any stage in life. }\end{array}$ \\
\hline $\begin{array}{l}\text { Adaptability to } \\
\text { learners need }\end{array}$ & $\begin{array}{l}\text { This method of learning takes place in an environment which suits } \\
\text { the need of the learner rather than learner adapting to needs of the } \\
\text { educational system. }\end{array}$ \\
\hline $\begin{array}{l}\text { - Self Paced } \\
\text { Learning }\end{array}$ & $\begin{array}{l}\text { The learning is self paced where the information can be reviewed } \\
\text { as many times as desired by the student.(for non-interactive sources } \\
\text { only) }\end{array}$ \\
\hline $\begin{array}{l}\text { Variety in } \\
\text { learning }\end{array}$ & $\begin{array}{l}\text { It provides the variety in learning techniques which make the } \\
\text { lessons very interesting for the students. The use of audio visual } \\
\text { aids promotes student participation in various exercises \& lessons } \\
\text { and thus helps in better retention s well. }\end{array}$ \\
\hline \multicolumn{2}{|c|}{ Disadvantages of E-Learning } \\
\hline $\begin{array}{l}\text { Lack of } \\
\text { interpersonal } \\
\text { touch }\end{array}$ & $\begin{array}{l}\text { There is a lack of mutual interaction between the students \& } \\
\text { teachers which many a time leaves the students dissatisfied. }\end{array}$ \\
\hline $\begin{array}{l}\text { - More time and } \\
\text { effort }\end{array}$ & $\begin{array}{l}\text { Learning designs and modules take lot of time and efforts to be } \\
\text { designed. }\end{array}$ \\
\hline - Expensive & $\begin{array}{l}\text { Last but not the least this kind of educational set up is very } \\
\text { expensive and not easily affordable by most of the small } \\
\text { organizations. }\end{array}$ \\
\hline
\end{tabular}




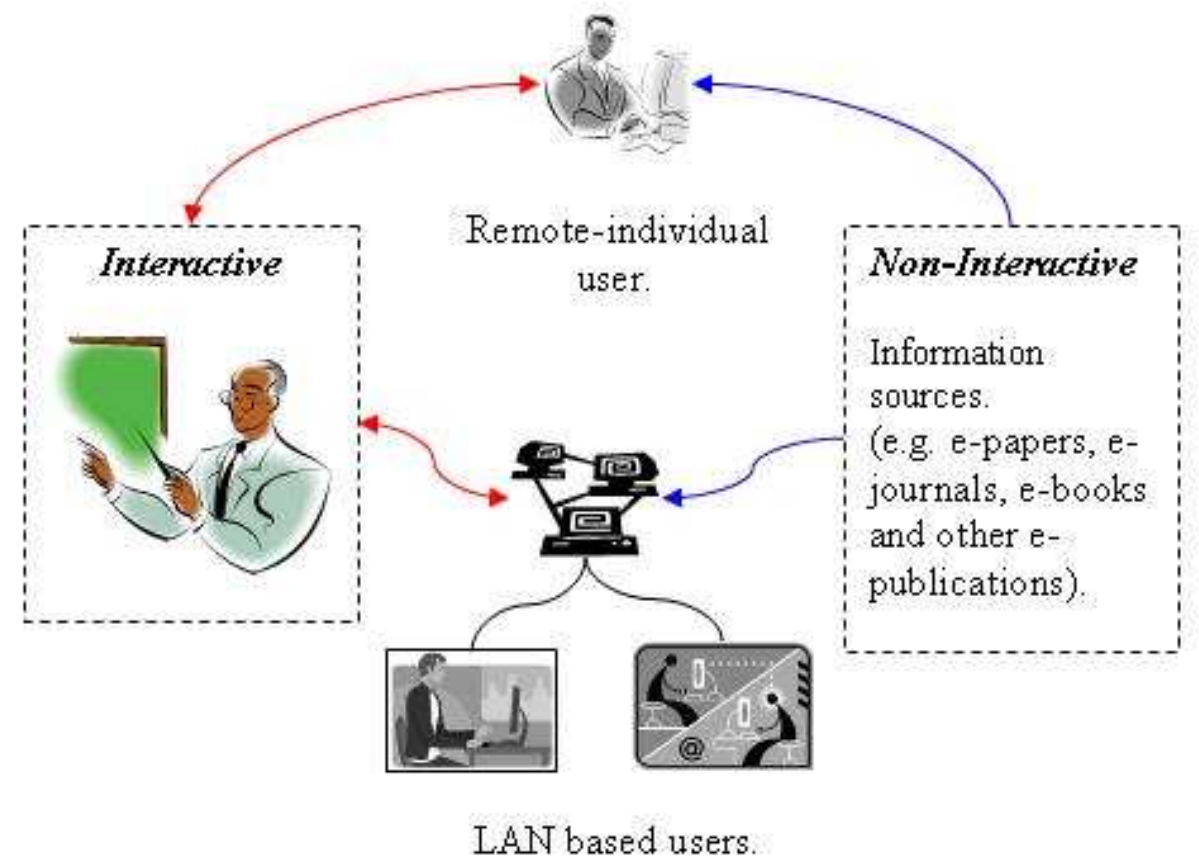

Figure 1,

Schematic Layout of E-learning setup. 


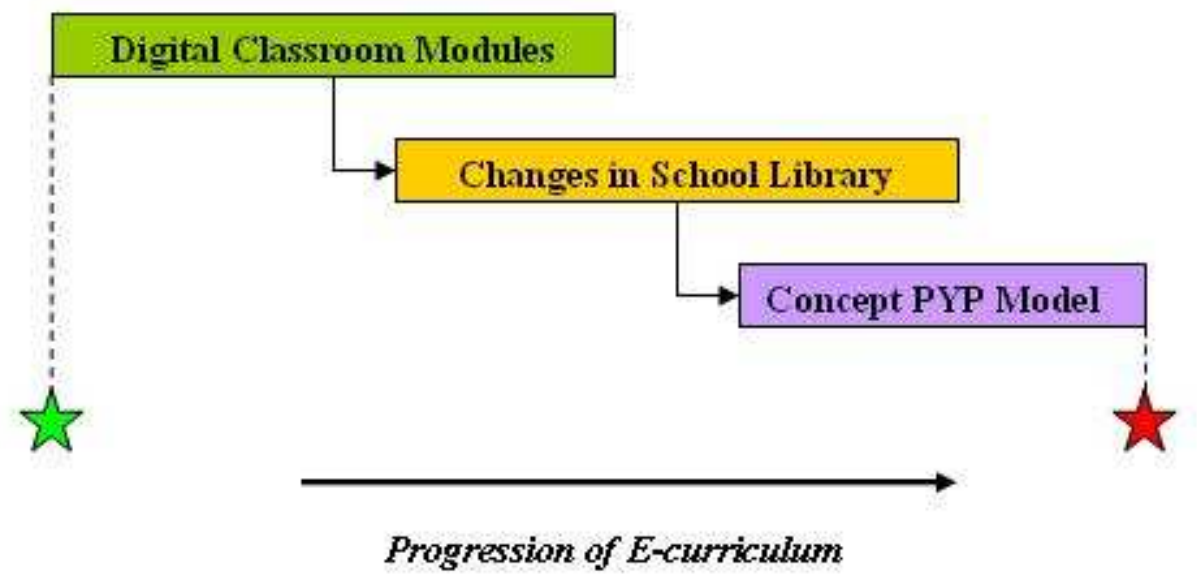

Legends

Initiating implementation of E-curriculum

W Complete implementation of E-curriculum

Figure 2,

Progression of E-curriculum- Key Elements \& Sequence. 


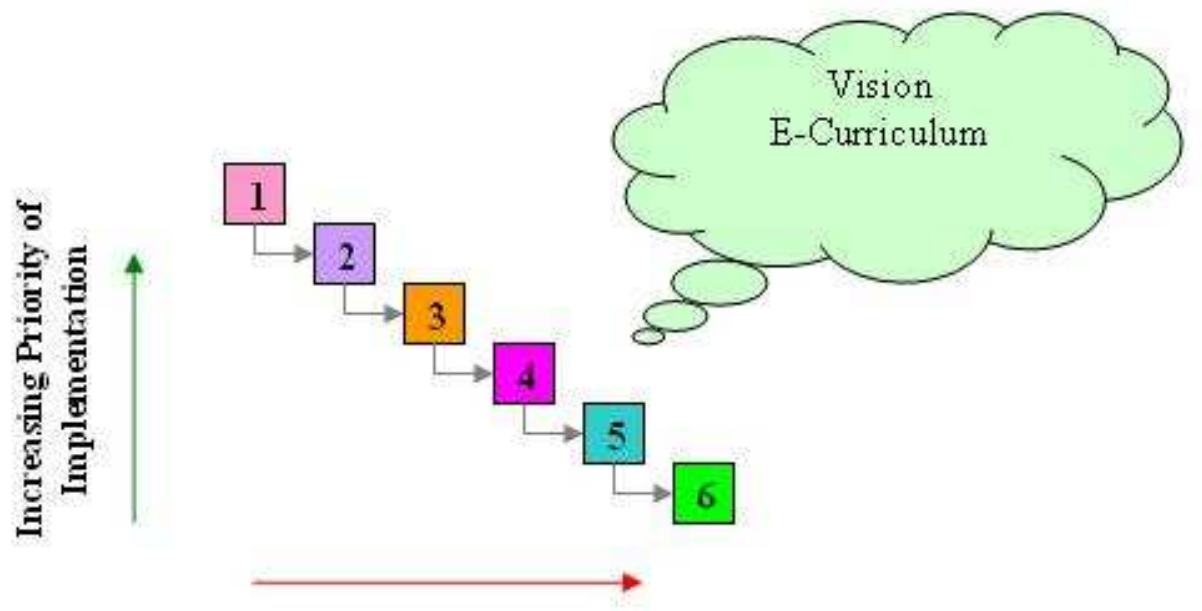

Sequence of Implementation

\section{Legends}

"1"- Multi media Technology

"2"- Hands on Computer Lab

"3"- Interactive White Board Technology

"4"- Educational Softwares

" 5 "- Computer Aided Education in Classrooms

"6"- Laptop Culture

Figure 3,

Digital Classroom Modules-Prioritization \& Sequence 


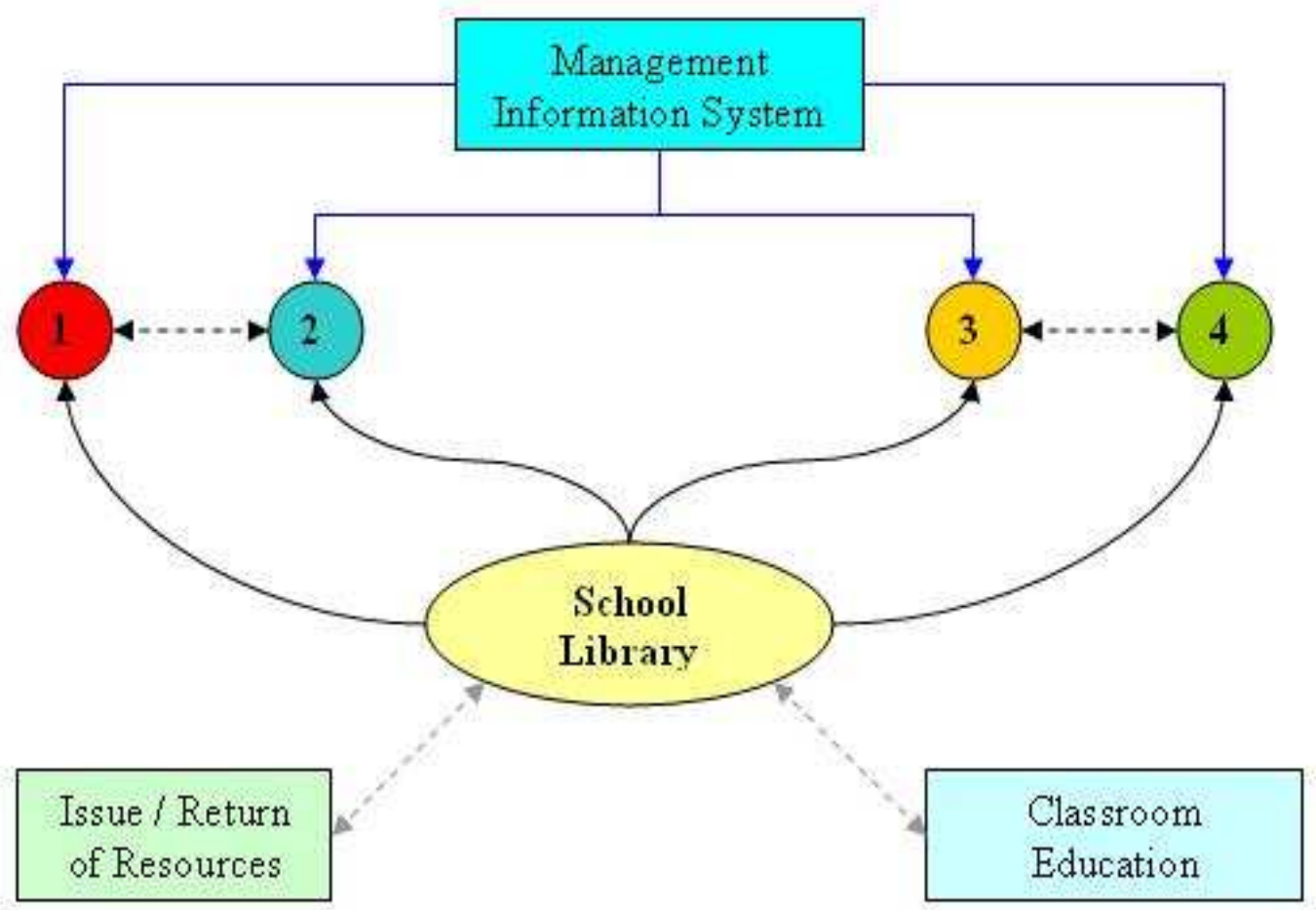

\section{Legends}

"1"-Inventory of Books

" 2 "-Information of Users

"3"-Resources for Digital Classroom Modules

"4"-Resources for PYP Teaching Module

Figure 4,

Schematic Layout of an Automated Library 


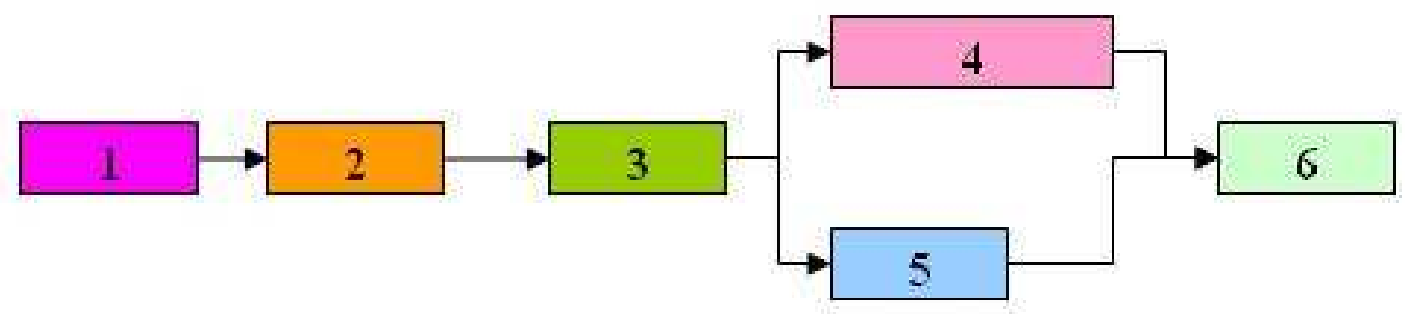

\section{Digitization Process}

\section{Legends}

"1"- Survey of Similar Libraries \& Available Technology

"2"- Development of Architectural Model

" 3 "- Identify ing Vendor and Placement of Order

"4"- Digitizing the Available Resources

“5"-Development of Meta data

"6"- Customizing User Access Rights

Figure 5,

Typical Digitization Process of a School Library 


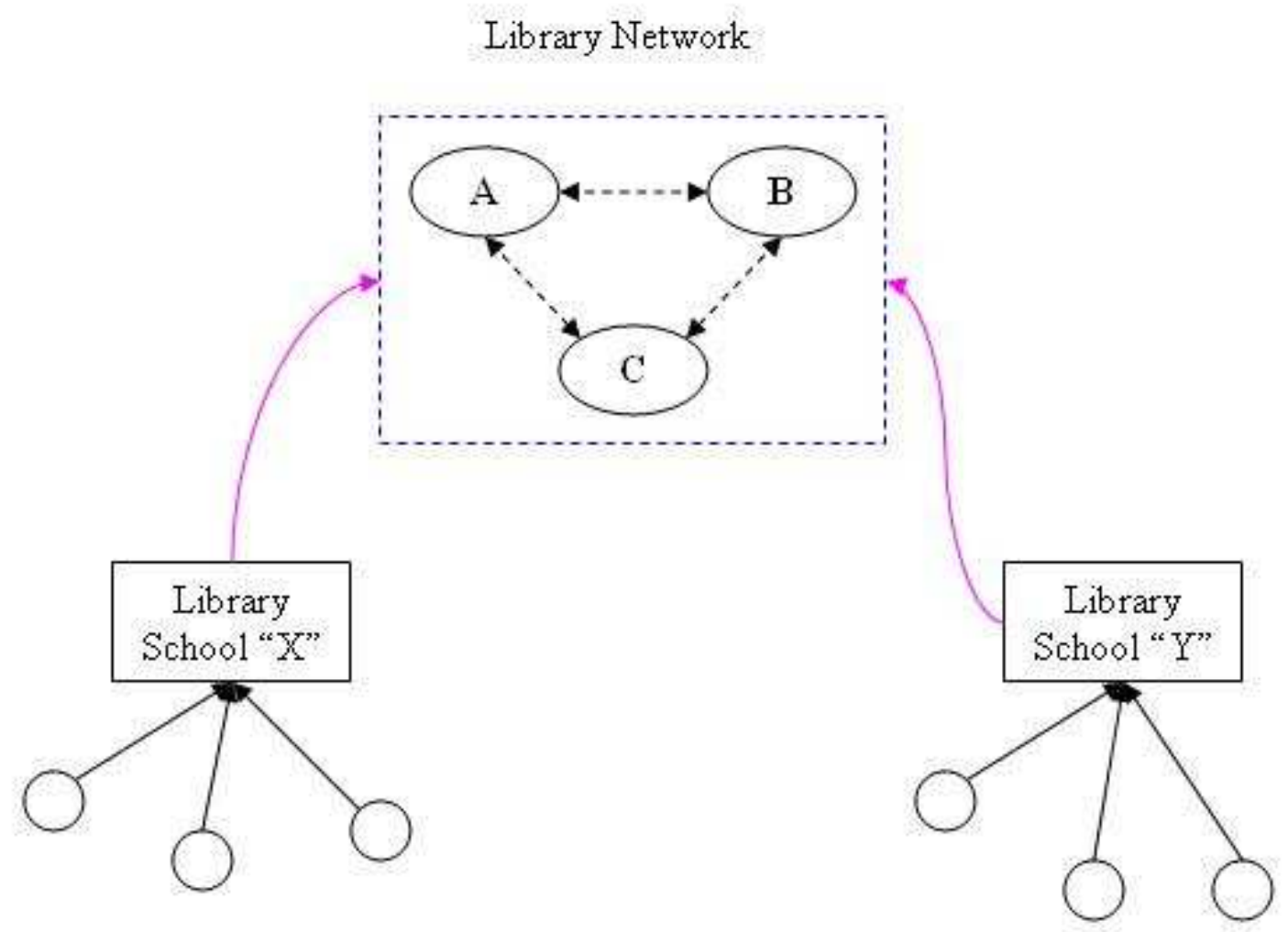

\section{Legends}

“A, B, C"-Information Centers for Library Network

-User at School Level

Figure 6,

Digital Network Based Library 
Filter- Level 2

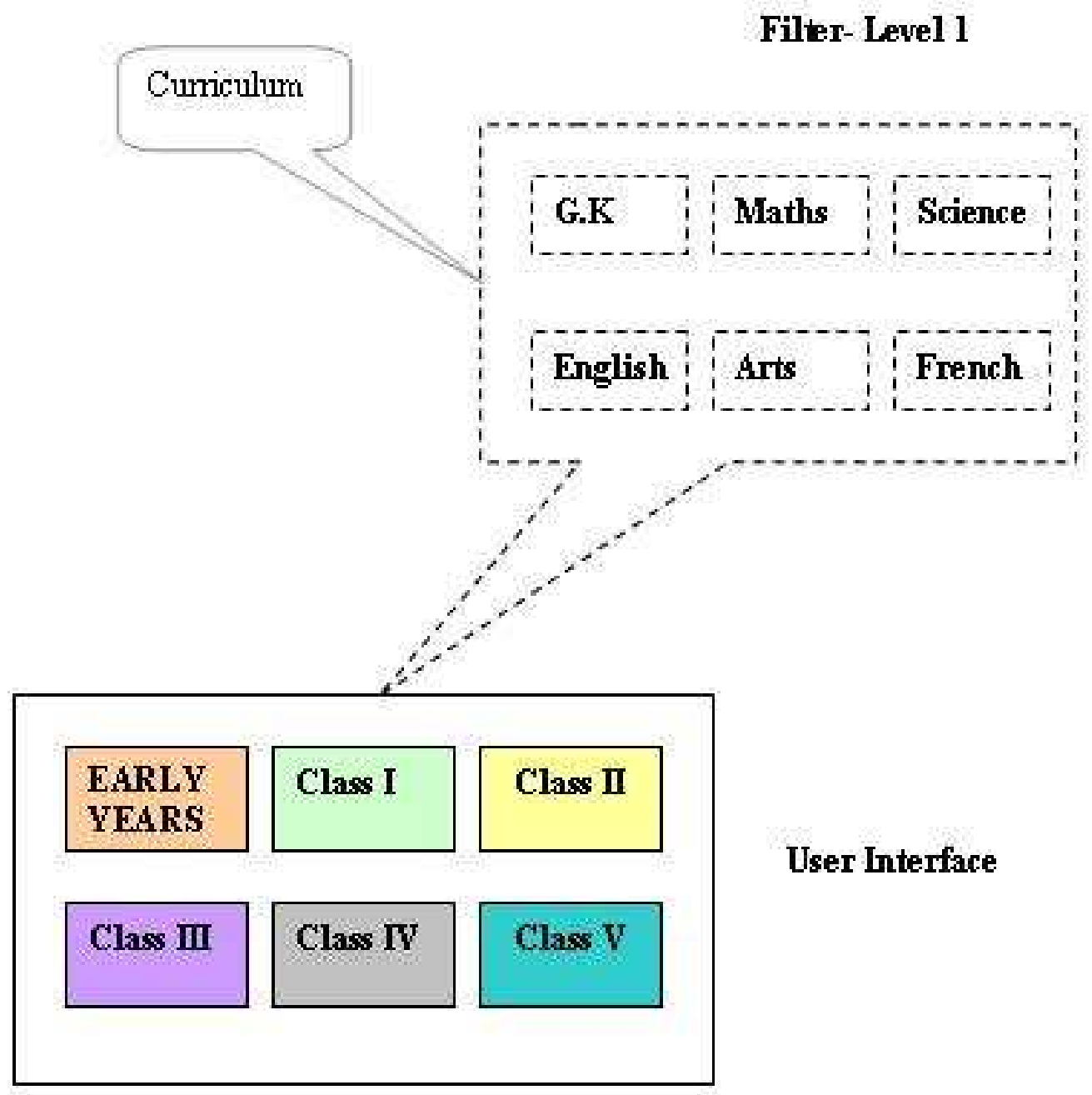

Figure 7,

Concept Teaching Model for Primary Years Programme (PYP) 